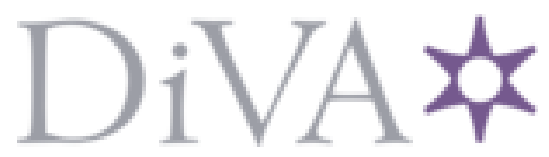

http://www.diva-portal.org

This is the published version of a paper published in Arts and Social Sciences Journal.

Citation for the original published paper (version of record):

Pemunta, N., Obara, T. (2012)

Toward a reconceptualization of the "urban" and "rural" as conceptual and analytical categories in the social sciences.

Arts and Social Sciences Journal, 3

Access to the published version may require subscription.

N.B. When citing this work, cite the original published paper.

Permanent link to this version:

http://urn.kb.se/resolve?urn=urn:nbn:se:Inu:diva-41721 


\title{
Toward a Reconceptualization of the "Urban" and "Rural" as Conceptual and Analytical Categories in the Social Sciences
}

\author{
NV Pemunta*, TB Obara \\ Noble Philanthropic Social Group NGO, BP 1306 Limbe, Republic of Cameroon. \\ *Correspondence to: N Vitalis Pemunta, vitalispemunta@gmail.com
}

Accepted: December 12, 2011; Published: June 6, 2012

\begin{abstract}
Globalization implies a general shift in spatio-temporal relations and the simultaneous deterritorialization of cultural phenomena orchestrated by the multiple global flows of people, ideas, and fashions. Within the context of globalization, it is troublesome for social scientists to continue using the "urban-rural" dichotomy as distinctive analytical and methodological categories because it tends to suggest a contingency in the pattern and character of social phenomena. This article sets out to theoretically rethink this conceptualization because of the multi-stranded and culturally embedded nature of human behavior in both space and time which has led to difficulties in delineating rigid subject boundaries today unlike in the past. Drawing on empirical data from diverse social phenomena, but particularly from the urban procurement and consumption of medicinal plant recipes, "dualistic" religious inclination and urban agriculture, we demonstrate that the geographic, spatio-temporal conceptualization of distinctive urban and rural phenomena are problematic. We suggest the notions of "urban-ruralism" and "rural-urbanism" as theoretical and methodological reconceptualizations to capture multiple embedded processes and to show that there exists a type of behavioral continuum/consistency because individuals have adopted hyphenated identities.
\end{abstract}

Keywords: Globalization; hyphenated identities; multi-stranded field; spatio-temporal relations; urban; rural; urbanruralism; rural-urbanism.

\section{Introduction}

The continuous deployment of the notion of "rural" and "urban" as distinctive analytical and methodological categories, suggesting the fixity of people and of cultures is out of touch with social reality, because both spaces are characterized by hybridity. This explains the weariness among contemporary sociologists and anthropologists of the "locality obsessed tradition" of research [1] implicit in the rural-urban dichotomy. In fact, rootedness in either a rural or an urban locality is no longer the vogue because of the subversion of ruralurban spaces by global ethnoscapes. The methodological catch phrases of global ethnography and multi-locale ethnography that faithfully capture the "complexity of the phenomenon of mobility, migration, and multiple belonging, rather than sedentarism" has replaced the "natural order of things" paradigm - the habit of viewing the world as portioned out into nation-states, and the cross-border movement of citizens as a secondary phenomenon [1]. In this light, even ethnography has been transformed from research within bounded geographical spaces into a travelling encounter characterized by multiple, repeated, short-term dwellings, for "... a viable representation of social life" [1], independent of place. This subversion of the "national order of things" [1] implies that social reality is no longer bounded and frozen in time and space in both rural and urban settings because of multiple flows of ideas, images, and fashions.

Rather, culture is fluid and deterritorialized, as captured by Ayse Caglar's concept of "hyphenated identities" and neither is anthropology the study of "the little community" as was the case in the past. We neither presume the existence of an a priori spatialized urban or rural community nor do we naturalize this community in keeping with Caglar's cautious note [2]. People of course find themselves entangled within multiple scales - local, national, regional, and international, which shape their ideas and reactions to social life situations. This calls for what Don Kalb and Herman Tak call "a critical junctions" perspective-one that explores the connections in space (and in and out of a place/in and out of a group), the relations through time, the internal and external relations of power and dependency, and what Wolf has called "the interstitial relations" between apparently separate institutional domains" [3]. This implies the need to see people as multiply located, communities as mobile, influenced by forces within their immediate environment and beyond, in terms of local and extra-local forces and to be conscious of multi-temporalities. Curiously enough, the urban masses, Homi Bhabha suggests, instead of completely renouncing "tradition," have rather "inscribed their social imaginary of both the metropolis and modernity, in terms of hybridity." He further maintains that the social sciences need to embrace changing trends in the contemporary world marked by "rapid shifts in people, 
objects and ideas" [4], shifts that have transformed the notion of the "field" as a fixed territorial space [5]. This is in tandem with the contemporary theoretical and methodological shift to multi-local and trans-local ethnography which are the hallmark and analytical currency of modern social science. The former spatiosocial/temporal dichotomy of separateness is untenable to the analysis of human social reality given the interconnectedness of the so-called rural and urban spheres. In addition, social scientists including sociologists and anthropologists are today interested in human behavior irrespective of place and time. We begin this intellectual enterprise by exploring what the concepts of "rural" and "urban" mean from their everyday banal usage and the social and cultural productions they seem to conjure/carry as well as their strictly sociological underpinnings.

\section{Uncoupling the Urban-Rural}

An endless number of metaphors have been used to delineate and distinguish the urban from the rural in common parlance. In the section that follows, we examine a few of these metaphors in an attempt to show how they do not really capture the independent specificity of place and presumed behavioral repertoires in themselves. This will prepare the appropriate framework for confronting the urban-rural riddle. We however begin with the huge debate around these concepts in Europe and America.

Although the urban-rural polarization has been fiercely debated by scholars in continental Europe and America, it has still been shown to be of analytical purchase. Arguments have been marshaled for the rejection of the category of "rural" because urban and rural spaces have become intertwined. Keith Hoggart for instance, points to the assimilation of urban and rural spaces, to similarities in causal processes across the urban-rural divide and argues that since the complexity of the structure-agency relationship is little understood, we need to simplify research designs by evaluating the circumstances under which similar structural contexts are associated with both similar and dissimilar behavioral outcomes. He however advocates the need to differentiate rural locations on account of their very different structural circumstances, while rural and urban spaces will often belong to the same population for purposes of theoretical sampling [6]. Nevertheless, theoretical definitions of rurality deployed in descriptive and sociocultural terms, Keith Halfacree argues, have been shown to be inadequate conceptualizations of space. This calls for an understanding of social representation and for a modified version of theory to enable the definition of the rural in terms of the disembodied cognitive structures which we use as rules and resources in order to foreground our everyday life experiences, through both discursive and non-discursive actions where such an "immaterial" definition may be assuming dominance over its locally based alternative [7]. In the Euro-American context, Paul Clocke and associates maintain, the polarization of the rural-urban divide is imbricated in unilineal agrarian political economy and rural economic restructuring [8]. Post-war agricultural modernization projects tended to "render rural spaces as sites for the playing out of a particular type of agricultural modernization based upon increasingly intensive methods and scale economies." Anything that was contrary to this blueprint such as upland farming regions, they point out, was considered as an anomaly, a "problem of agricultural adjustment" and not as a potentially different pathway to rural development. Drawing on Newby, they call for a holistic theory of society that link social to spatial structure, and that gives the social primacy, as well as for a revised political economy of rural space so as to foreground the distinctive features of rural life, but without isolating it conceptually from broader social science theoretical and conceptual trends and interpretations. The ruralurban opposition, Mormont [9], notes, is socially constructed and the rural exists primarily as "a representation and not an ascertained reality that serves to analyze both the social and space-or rather to analyze the social while defining space-borne and ascertained reality as interpreted by social agents". Rurality therefore, is in the mind of the beholder "dependent on an individual's circumstances," his self-definition in relation to prevailing social cleavages, a source of self-identification and common cause [9]. This dovetails with Paul Clocke's view that rurality is an encompassing label about space, place and society in the Western world, which is embedded in all kinds of cultural meanings: from the idyllic to the oppressive and "as a material object of lifestyle desire." This distinction is vested in the oppositional positioning of the rural to the urban. The very dynamism of rurality and the conditions of rural life make rural place and rural political economy constitutive of important shifts in the material manifestation of rurality. Rural and urban spaces are fluid and a phenomenon such as in-migration from urban to rural areas is accompanied by the diffusion of the key attributes of urban living and levels of expectation thereby transforming these communities. The advent of information and communication technology (ICT) has also mediated this spatial change leading to cultural urbanization of most places in the Western world. The overall effect of these changes has been the urbanization of the rural and the ruralization of the urban, despite differences in scale and trend among nations. The dynamic relationship between space and society, Mormont [9], points out, "has rendered traditional divisions between the rural and urban increasingly indistinct" because of the existence of a multiplicity of overlapping social spaces within the same 
geographical area, that characterizes rurality, including blurred city and countryside, although significant differences persists. Rurality is however, not tantamount to a takeover of the rural by urban values and forms. He cites that recent land developments in North America have reportedly produced suburbs, shopping centers, theme parks, executive estates and tourist development among others. These "hybrid settings" or "pseudorural landscapes," and creations, which have been produced by the bringing of nature-into-the-city, as much to the spread-of-the-city-into-the-countryside, opens out imaginative spaces of the rural in these hybrid spaces. What this ruralization of the metropolis demonstrates is that the rural-urban are not isolated islands, not impermeable geographical and social spaces. They tend to transform each other, thereby challenging ruralurban polarities and calling for the need to be wary about and to avoid, arbitrary spatial boundaries of available data and to look beyond the physical and social construction of boundaries, intersections between social construction and rural practice. For instance, the Edmonton Mall in Canada has among others, suburban indoor shopping centers, a one-hectare lake replete with dolphins, and sharks, a golf course, a water park, and zoological collections of animals in cages and aquariums [10].

The polarization of the "rural-urban" divide, although the scholars mentioned above demonstrate that these practices are not spatially limited, suggests that, this fictitious dichotomy is cultural and embedded in Euro-American development model particularly in agrarian political economy and rural restructuring, and also in policies and practices in Euro-America, which have been transported and uncritically adopted to reflect African realities since colonial days.

During the colonial epoch in Africa the "urban" designated the European settlement. This was a reference to the seat of colonial administrative power and white residence. This area was usually far more "developed" than the rural habitat of the natives. It usually had a prison, administrative offices, a public place, a health post to offer health services to the administrators most of whom were foreigners. It was at times equally the site of the church or "new religion" and the location of the colonial police. It was a guarded and segregated space with security in contrast to the settlement of the local inhabitants. It represented civilization in contrast to tradition, which was held alongside "barbarism" and "superstition" to inhabit the space occupied by the "natives."

In the wake of the incurable HIV/AIDS pandemic, the urban has come to be attributed with disease particularly HIV/AIDS and other sexually transmissible diseases (STDs). STDs with HIV/AIDS inclusive are held to be contracted through prostitution, an immoral act. The rural masses have no prior experience with a disease like HIV/AIDS except when a patient comes home as part of his/her life's journey when s/he has taken a turn for the worse from the pandemic. It is held that the urban setting is characterized by a free fall in moral values. In the minds and thinking of some of the rural masses, morals are witnessing a free fall in urban areas where anonymity is the norm. At the same time, we know that rural prostitution equally exist although the scale and medium of exchange might not be the same. Given the networking between rural and urban areas, it is possible for every transmissible disease to be transmitted from one locale to the other at the speed of lightening.

Throughout sub-Saharan Africa, higher HIV infection risk has been reported among urban migrants than in rural areas. This exposes urban residents to greater risk of HIV infection than rural residents, even if the number of sexual partners does not differ between rural and urban residents $[10,11]$. Some scholars suggest that the number of sexual partners increases after migration to an urban area. By moving from rural home, individuals are liberated from the constraints imposed in social rules and regulations surrounding sexual conduct in their rural areas of origin and are thus more able to engage more freely in sexual networking [12]. However, the link between urban migration and HIV risk has become blurred of late, and rural-urban migration is no longer associated with increased risk of HIV infection in some areas of sub-Saharan Africa [13]. Aware of the higher HIV prevalence in urban areas, some migrants change their sexual behavior in response to the increased risk [14]. Writing on Malawi, Philip Anglewicz explains the higher risk of infection among migrants in terms of separation from spouses as a result of labor migration given the seasonal availability of labor in much of sub-Saharan Africa such as mines in South Africa, factory work in Zimbabwe, which often leads to temporary migration during which migrants live at their place of work, while the spouse stays behind. Separated from a spouse, migrants are more likely to engage in sexual activity with more risky individuals [15], and have more overall sexual partners than permanent rural residents [12]. Labor migrants are not only more likely to be HIVinfected, but also serve as conduits of HIV to rural areas by infecting their non-migrating spouses or sexual partners. Additionally, these migrants face the risk of infection, not only through sexual activity while separated from a spouse, but also from the spouse who may have become HIV-infected through infidelity while permanently residing at the migrant's home [13-15]. 
The urban is further equated with money. Everyone who lives in town is said to be rich just like any individual who has migrated to Europe, the United States, Canada, Australia or who has a White skin. In contrast to this, the rural is attributed with and synonymous to poverty. Rural women can always graphically relate their experiences with the Structural Adjustment Policy (SAP). They are poor because it is the town people who decide on the prices of their raw materials. In the same manner, the rural is said to deal with primary production and the urban with real production-transformation of foodstuff into finished products. This is reminiscent to the idea of center and periphery in the world system theory. Michael Woods has however pointed out that, although poverty has been conventionally recognized as being more pervasive in rural areas worldwide, in the global South, more visible concentration of poverty in urban areas is seen. In reality, the rate of poverty in the United States is higher in rural counties (14.8\% in 2000) than in metropolitan counties (11.9\%), and substantial levels of poverty were identified in several case study areas in England and Wales by researchers in the 1990s [16].

Another perceived characteristic of the urban landscape is literacy in contrast to illiteracy in the rural milieu. The former setting is further equated with progress and the latter with conservatism. Urbanites are generally believed to be open to new ideas and willing to try certain things on a trial and error basis. The rural masses on the other hand are seen as prone to tradition, unchanging, and unwelcoming to change and willing to hang onto traditional values and practices. But the disposition to new experience varies likewise modernity does not necessarily lead to a total break away with traditional ways of doing things as we will demonstrate through the growth of the traditional medicine street pharmacy, syncretic religious inclination and the phenomenon of urban agriculture later on.

Additionally, expressions such as "boutoukou"1 and "villageois" are sometimes used in Cameroon to designate people usually in town who are unable to live with the changing times in terms of their dressing code, consumption habits and ways of thinking and expressing themselves. Generally, they epitomize particular ways of feeling, acting and doing things, which are considered as non-urban. That is, they do not comply with the implicit rules governing urban lifestyles and conduct. This is reflexive of the view held by Alex Inkeles and David Smith according to which in socio-psychological terms, modernization is "a process of change in ways of perceiving, expressing and valuing." The "modern" following them becomes "a mode of individual functioning, a set of dispositions to act in certain ways [17]. Historically, modernity is an epoch stretching from the emergence and expansion of capitalism, industrialization, scientific rationalism, nationalism, and state claims to military power and the surveillance of citizens. This conceptualization of modernity presents it as a fluid historical process underpinned by cultural transformations and the wide range of meanings people attribute to such change [18].

Within the context of ethnicity and multiparty politics in Cameroon, the urban and the rural have been used to designate natives (belonging, having an attachment to the soil) and non-natives who have no affiliation to the soil. Therefore, they cannot offer sacrifices to the ancestors of the land. Most urban areas have government delegates who are always sons of the soil because the implicit assumption is that only natives can better serve the interests of their people. We may however designate this group of elites as "rural-urban." When someone talks of his native town, it means the urban area near his village, the town/village where he was born, where he has authority, where he can put up his candidature for electoral contest. Within the reconceptualization of democracy and ethnicity, non-natives do not have this right. In fact, the Yaounde government put ethnicity in capital letters in the January 1996 Constitution through the twin concepts of autotone and allogene. This tacitly makes political participation contingent upon affiliation to the soil [19] in the vote bank politics of Cameroon.

The rural is further linked to bushes, the forest. Moreover, the urban as lacking bushes, forest and tradition, despite its being a melting pot for various cultural traditions. Ironically, rural areas are increasingly suffering from deforestation and global warming is affecting both environments, though in different degrees. Both the rural and urban masses equally resort to tradition thereby appropriating local knowledge systems and beliefs in the resolution of their problems: search for employment, restoration of health, wading off bad luck, attracting more love from partners among others. The African urban sphere has thus witnessed the proliferation of traditional medicine pharmacies, medicinal plant vendors, and all types of traditional medical systems, soothsayers, spiritualists and witchdoctors.

\footnotetext{
${ }^{1}$ This refers to somebody who can be easily deceived because of his/her presumed lack of urban experience.

2 Inhabitant of a village, when taken in its literal French sense. In this context and derogatorily, somebody who is gullible. Somebody who dresses poorly and at times in rags unlike those in town that dress well and tailor their dress codes in function of particular occasions.
} 


\subsection{Definition of concepts}

In a bid to define the word urban, let us start with urbanization. It implies an increase in the proportion of the population living in an area - the process of people moving to cities or other densely settled areas. Urbanization has two facets as people move from rural to urban settings, they engage in primarily non-rural activities. Secondly, there is a change in their lifestyles in terms of values, attitudes, and behaviour [20].

From the foregoing, rural-urban migration is characterized by an increment in the density, size, and economic functions of the population, psychological and behavioural changes as well as independent factors. The above definition somehow resonates with some elements of Paul Clocke's theoretical frames of rurality first as dominated by extensive land use, an entanglement of buildings and extensive landscapes, and as engendering a cohesive identity. However, Clocke goes on to point out that the functional rural has now been transformed by the dynamics of national and international political economy which have often been seen to operate on an aspatial basis. He articulates the call to stop seeing the rural as self-contained, but rather, to see what happens in the so-called rural sphere as intertwined with the urban, to take note of extra-local factors. Secondly, he maintains that, political-economic concepts can be used to clarify the nature and position of the rural in terms of the social production of existence. Thirdly, that as a socially constructed reality, "rurality" lies in the fascinating world of social, cultural, and moral values which have become associated with rurality, rural spaces, and rural life so as to study the intersection of practice, behaviour; decision-making, and performances are contextualized and influenced by the social and cultural meanings attached to rural places [10]. Similarly, Hoggart called for the need to discard the rural-urban dichotomy: "to do away with the rural"... and to seek out sectorial research spanning across various rural-urban distinctions. Rural and urban issues are intertwined, but are more accentuated in rural areas, although the "rural dimension" is not incompatible with "politicaleconomic approaches particularly because the particularities of time and place cannot be" disentangled from the social construction of certain time-places as rural [6]. Even the word urban is relative because its definition is country-bound especially in terms of demographic criteria which varies from one country to another. For instance, in France, Israel, and Argentina, 2000 people constitute an urban area. In the United States, Mexico, and Venezuela, the figure is 2500,5000 in Belgium and Ghana respectively and 10,000 people in Greece. By Cameroonian standards, an urban centre is any agglomeration of over 5000 people engaged in mainly nonrural activities [20].

The "rural" is usually defined in opposition to the "urban." This contrastive approach masks the unique character of difference in terms of the degree of "rurality." It is what is not urban Alejandro Portes [21] maintains, that has been variously defined in terms of ideal-typical polarities: tradition versus modernity even when there is alternative modernity. Similarly, Gusfield [22] observes that the tradition-modernity polarity is not based on two sets of independent empirical observations, but rather on one such and its logical implication for the other. Other scholars have fallen into the dichotomy trap as reflected by Durkheim's mechanic versus organic solidarity [23], Spencer's feudal - agricultural versus urban industrial societies, when strictly agricultural towns exist [24], Bogardus' evolution from undifferentiated homogeneity to differentiated heterogeneity, the folk-urban typology of Ralp Linton [24], inscriptive versus achievement-oriented cultures [21] and the list is endless. We will now consider three social phenomena to demonstrate the falsity of the urban-rural dichotomy and to advocate for "urban-ruralism" and "rural-urbanism" as analytical and methodological concepts that capture the hyphenated identities of individuals as social actors in their everyday behaviour.

\section{The Urban as the Place of Traditional Medicine}

Prompted by the unhygienic conditions under which traditional medicine recipes were being sold in urban Yaounde, we decided to conduct a study to understand why in the face of "modernity" and the urban monopoly of modern health care infrastructure people still resort to traditional medicine. Vendors and their customers were targeted through "convenience" sampling. Interviewees out of their own willingness were recruited without any attempt to achieve representation. Combining both qualitative and quantitative research methodology, 78 vendors were interviewed whereas 199 customers were questioned. Of this number, $79.5 \%$ were men and $20.5 \%$ were women. Moreover, $60.9 \%$ of our sample of 199 customers were men and only 70 (39.1\%) were women. Participant observation equally took place for several weeks. We followed several vendors through the harvesting process and into the homes of their clients in different quarters. We performed multi-sited ethnography.

The study showed a strong recourse to traditional therapy by the urban masses independent of class, socioeconomic and professional status. Most customers (85\%) had educational levels between primary and university. We realized that $37.4 \%$ of our respondents had elementary primary education, $31.2 \%$ secondary 
education, $16.4 \%$ university level education whereas only a meager $15 \%$ have never been to school. Customers were mostly adults in their prime productive years ( 20 and 45 years).

This finding suggests that the products are not age-specific, although most people were buying for themselves and for members of their families and neighbors. This further suggests that in contrast to popular belief, these African pharmacies are not predominantly patronized by the uneducated and the older generation. We agree with Smith and Inkeles [17] that little empirical evidence is available to support the claim that education has a very large impact in making men modern, at least in the developing countries.

Further, religion has a marginal role to play in people's health seeking preferences. More than 50 (53.6\%) respondents claimed they were Christians, 31.8\% Muslims, and $14.6 \%$ claimed to be animists. Religious affiliation or the idea of living in town hardly uproots people from their ancient beliefs and practices. This turns to suggest that Christianity is marginal to people's health seeking behavior and practices. As a matter of fact, most urbanites are rural peoples at heart. They simultaneously practice African traditional religion and Christianity as reflected by the wearing of outward paraphernalia like medallion, fetishes, and other objects [25]. Religious background may not always influence health-seeking behavior at least from the findings of this study. This ties in with Kenneth Little's view that:

There are however considerable differences in the extent to which particular people and ethnic groups have given up their former habits. Indeed, in most cases, it occurs that the African individual moving out of the tribal area continues to be influenced by tribal culture. [26]

As to their motivations, we realized that urbanites have resorted to a division of labor in terms of health-seeking behavior from the standpoint of disease etiology. Individual psychology about recovery and the impact of early socialization has led to recourse to traditional medicine even in an urban context. Additionally, recourse to medicinal plant recipes is due to the presumed negative side effects of modern medicine as well as social tensions in urban areas. We elaborate on these factors one at a time.

\subsection{Disease etiology}

Indigenous medicines are held to be effective against common ailments such as malaria and venereal diseases. It seems that because of urban poverty, there is usually non-compliance with administration procedures when biomedicines are taken as therapy. Following George Foster and Barbara Anderson [27], lay people's therapeutic choices are partly determined through the recognition of the disease symptoms and its perception in relation to other illnesses. Following various informants, an antidote against poison can lead to its being vomited out immediately. Scarification can equally lead to the poison being ejected from the human organism instantaneously. In the same light, infertility, sexual impotence, and witchcraft are all seen as belonging to the domain of traditional medicine.

\subsection{Psychological factors}

Knowledge about the therapeutic properties of various medicinal plants are held to have been acquired in the village through socialization. Most individuals have therefore been socialized into believing that only particular herbs can offer relief against specific illness episodes and not biomedicine. This turns to reflect the emic dimension between cause, diagnosis, and prognosis, which holds that when afflicted by a similar disease, influences the way both individuals and families alike respond to a particular episode. Some bought indigenous drugs because they or members of their social networks had successfully used it in alleviating particular illness episodes. Foster and Anderson have noted that:

The fact remains that no scientific medical system completely satisfies all the health needs of a nation. Even in countries with highly developed healthcare systems, many people, under certain conditions, will turn to non-established forms of medical help such as faith healers, herbal doctors and the like. "Alternate" forms of medical care fill social, psychological, and perhaps organic health needs, which at least for some people, remain unmet by physicians and associated health care services. [22]

\subsection{Negative effects of modern medicine}

Modern medicines are perceived to produce certain undesirable side effects. For instance, anti-malarial drugs are said to be allergic to certain individuals. The drugs are further held to be toxic and poisonous. To compound matter, respondents maintained that chemotherapy stays longer in the human organism unlike traditional drugs. However, those who combine both systems of medicine at the same time held that they do so to reinforce the other. Modern medicines are further said to be too constraining, as they have to be taken at particular times of the day unlike traditional drugs. 


\subsection{Social tensions and conflicts of interest}

Urban centers are fraught with social tensions. Despite the informality of social relations, they are at the same time conflicting. To cope with this, some people wear personal charms to wade off any harm. They wear medallion, hang charms and amulets in their houses, and wear rings and bracelets serving both magical and ornamental purposes. Following Geoffrey Parrinder such objects are supposed to wade off bad luck, evil spirits, and diseases. In line with the same logic, he maintains that bundles of feathers are put in sticks in fields or laid on tone piles as safeguards against thieves and blight [28]. Some people carry on themselves the barks of certain trees to influence top authorities or events like court cases in their favor. Some want more love, care, and compassion from their partners and to achieve this, they go for love portions. Ingredients for the preparation of various charms and concoctions are found in the urban traditional medicine pharmacy. This recourse to tradition can be explained in relation to Bhabha's concept of cultural hybridity. He argues that though "cultures in the rural/urban, North/South may be contingent to modernity, discontinuous or in contention with it, resistant to its oppressive, assimilationist technologies; they also display the cultural hybridity of their borderline conditions to "translate" and therefore re-inscribe the social imaginary of both metropolis and modernity." Urbanites may thus be said to "display the cultural hybridity of borderline conditions" by appropriating traditional ideas and practices to solve problems in the urban context. Instead of completely denouncing "tradition," they have "inscribed their social imaginary of both the metropolis and modernity" [4], on the one hand and the rural on the other hand in the quest for solutions to their problems in the urban milieu. For instance, they sometimes consult both modern medical practitioners and traditional healers simultaneously.

\subsection{Urban anonymity and confidentiality}

Perhaps, the most salient finding was that unlike at official healthcare systems such as hospitals, clinics, pharmacies where the patient needs to be identified, there is no such protocol at the roadside traditional medicine pharmacy. Everything goes on in anonymity except with regular customers who are well known. You can at times hear vendors addressing them using either their names or professional titles. Customers are at times observed standing far away and beckoning on the salesman especially when women are around and the patient is suffering from a venereal disease "diseases of shame". Like the transposition of traditional medicine in the urban landscape, agriculture, a formerly rural activity has equally stretched its tentacles into the urban environment partly as a recreation of tradition and because of economic hard times orchestrated by the SAP of the 1980s and 1990s.

\section{Urban Agriculture}

The advent of agriculture in the urban landscape further challenges the uncritical idea of an urban-rural dichotomy. For several decades, agriculture was conceived as a rural activity and urban areas defined as "having people who are engaged in non-agricultural activities" [20]. This is despite the growth of strictly agricultural towns such as Tiko and Mundoni in Southwest Cameroon. The City Farmer Canada's Office of Urban Agriculture (CFCOUA), dates the beginning of urban agriculture to the colonial days. From Europe, the colonial masters took along with them exotic vegetables and ornamental crops, which were purportedly grown to feed the European settlers and to beautify their residences. The cultivation of vegetables was accordingly confined to the residences of European civil servants and merchants and the castles and forts, which served as both the seat of government and the homes of the colonial administrators.

The CFCOUA further reports that some 200 years ago in the face of widespread hunger and poverty in Germany and other European countries, "gardens for the poor" emerged. Rapid industrialization, accompanied by urbanization and migration, forced large numbers of people into dismissal living conditions. Urban gardeners were one official response."

In the face of SAP and widespread poverty of the late 1980s and early 1990s, urban agriculture became a source of livelihood for both the poor and the rich alike in most capital cities of countries of the Less Developed World. The SAP led to high cost of living for urban households, loss of jobs, massive retrenchment and general fall in living standards. To downplay the undesirable effects of economic hardship, alternative coping strategies among which is urban agriculture saw the light of day.

The practice of urban agriculture cuts across socioeconomic groups as both the poor and the rich alike indulge in it. The main difference is expressed in terms of access to resources and the driving force behind the activity. According to Mawoneke and King [29], farming households are better off in most respects than nonfarming households are. Even after subtracting direct input costs, the farmers have a positive net benefit, although it is a marginal one. It is an important source of income. For instance, it provides farmers with important employment and food provisioning opportunities that would otherwise not be available to an ever- 
increasing urban population as the population resorted to the growing of basic foodstuff in both urban and peri-urban areas leading to the improvement of their nutritional status.

Some people became urban cultivators merely as a way of spending their extra time after work in both the private and public sectors of the economy. Others wanted to keep up with their traditional activities having grown up in peasant households in the countryside, which largely depended on agriculture. Because of unequal exchange between food cultivators and small-scale traders who usually link both rural and urban areas, some farmers have now moved into the urban sphere where they carry out their activities and sale the produce directly on the market either by themselves or through various associations.

Despite its proven economic and nutritional value, governments disparaged it because of its perceived environmental and health consequences: breeding grounds for mosquitoes, snakes and rodents, tenure insecurity and encroaching land development. Other common arguments against urban cultivation mainly relate to high rates of soil erosion and chemical pollution of soil and water owing to chemical and pesticide use in crop and vegetable cultivation. Nevertheless, most of these criticisms are merely presumptions with no basis in empirical data. Following Thembile Mawoneke and Bowdin King, recent research shows that pollution of urban rivers is caused mainly by industrial effluent and sewage disposal rather than by urban cultivation. The contribution of agrochemical to water pollution is minimal [29]. Almost all over Africa, farms have sprouted up in both urban and peri-urban areas of towns such as Maputo, Kano, Kampala, Nairobi, and Yaounde among others. In the case of Cameroon in particular, officials of the Ministry of Health and Environment took an uncompromising stance against the practice pointing out that it would lead to breeding grounds for mosquitoes, which transmit malaria, provide habitats for snakes and other rodents that could be dangerous to human health. Nevertheless, in the heat of economic hard times, the population paid a deaf ear to the injunction. The scale has now increased from mere gardens to large-scale farms. Unlike in the past when the foodstuffs produced were mostly meant for household consumption, most of what is produced today is meant for sale. There are in fact urban farmers in most capital cities of the Less Developed World.

\section{Religious Syncretism}

There is the juxtaposition of "syncretic" elements in urban life, which attest to double cultural belonging and multiple identities. In other words, urban dwellers are caught between tradition and modernity. Religion is equally one of those areas where the impact of tradition on modernity is very clear. Lomo Myazhiom maintains that religion has political functions at the service of the state as well as economic functions like the accumulation of riches by the priests and the bourgeoisies. Each of these classes therefore has its own beliefs and rites that conform to its interest. This dynamism finds its realization and effective value in the difficult and intricate relationship between tradition and modernity [30]. There is therefore the need for materials to foster this tradition which the urban cultural medicine service sector provides.

Even Christians are alleged to carry on themselves medallion, barks of trees and other objects for protective purposes $[25,26,28,32,35]$ even when they are going to church leading Pierre Titi Nwel to baptise this phenomenon as the "ruralization" of Christianity. He poignantly points to the "paganization" of Christianity, and to the fact that despite conversion to Christianity or Islam, there is (in)direct recourse to ancestral ways on several occasions in daily life [25]. Most Africans still carry objects on themselves for either protection or to influence events in their favour. Similarly, Jean Marc Ela has pointed out that employers see mechanical accidents as an indication of a magico-religious act, and not as a normal event. Furthermore, accusations of sorcery are not rare in towns. People equally attribute the loss of a case to occultist practices [31]. Prison sentences based on mere accusations of witchcraft in the courts of the Eastern province of Cameroon as well as the use of supernatural powers to win football matches have been documented [31, 35].

As a matter of fact, all facets of African life are rooted in traditional beliefs and practices despite place and time. Ela Jean Marc sees the universe to be relational and systemic. With regards to illness, he has this to say:

The whole universe of illness finds its socio-cultural underpinnings in traditional beliefs. We see university professors consulting diviners or soothsayers so as to get promotion. Recourse to magicians is an omnipresent practice in African towns where black Islam has impregnated the mind. Health agents do not hesitate to take members of their families to native doctors for treatment where they question the spiritual or ancestral medium through whom tradition is addressed to find a response to their questions. In response to growing insecurity, sects are proliferating in towns among jobless youths, small employers.... (This is our own translation from the original version in French) [31] 
According to him, when confronted with illness in town, we witness a type of recourse to what has traditionally been "rejected" in the face of modernity. Healers have not lost their raison d'être despite the implantation of the western medical system whose efficiency has been proven in the presence of the crisis in African society. Faced with the shortcomings of this system, traditional healers have implanted their "clinics" in the quarters of the capital city. Everywhere, sports have remained tied to the practice of witchcraft. In academic institutions, pupils and students alike are alleged to attribute their failure in examinations to occultist practices. He notes that everything is happening as if the rationality of tradition has remained a norm of reference in many domains that have been invaded by scientific knowledge [31]. Similarly, Eric De Rosny has shown that in Douala (Cameroon) belief in Miengo has not petered out under the influence of modernization. The relationship with the invisible world has remained the centre of gravity in the universe of disease as evidenced by the public practices of urban healers, which De Rosny came across. He witnessed nocturnal therapeutic sessions which cut across socioeconomic class and religious orientation [32].

This contrasts sharply with attitudes towards shamanism. In their study of Korea's traditional medicine and shamanism, Linda Connor and Geoffrey Samuel [33] note that some people distance themselves from shamanism as a way of asserting their own claims of "modernity". Meanwhile Stacy Pigg [34] observes that "the idea of the 'modern' generates a sense of difference while at the same time holding out the promise of inclusion in the global cosmopolitan culture." Those who condemn traditional medicine, affirm their aspirations of being included in the global cosmopolitan culture. They thus invoke "modernity's" core tenet of trouncing "superstition" and to the fact that the definition of tradition is part of a social struggle, since as Connor and Samuel argue "modernity" does not inevitably vanquish "superstitions", although this tenet is intrinsic to modernity's world view, and those who have invested in modernity have every incentive to tell linear narratives about themselves [33]. We came across well learned individuals who were procuring traditional medicines.

The examples highlighted above clearly show that the rural environment has remained a reference point for the uncertainties and difficulties confronting the new city dweller. There is therefore the need for adaptation to his new environment. The maintenance of communication links with his rural environment now comes into play. Village associations, the celebration of births, initiations, marriages, and deaths in the village further reinforce this view. City dwellers through their tribal associations offer much to their villages. This may be through occasional donations for the construction of schools, dispensaries, religious feast to reinforce health and general wellbeing.

In fact, migration has been a significant catalyst for the transgression of rural and urban space as migrants often live in two worlds simultaneously. In his discussion of the economic and symbolic significance of the village in most low-income migrant's aspirations, Harri Englund, for instance, maintains that migration to urban areas hardly leads to permanent settlement because their desire is to improve life conditions in villages. This implies the simultaneous and overlapping presence of urban and rural spaces in migrant's lives. Rural migrants, in Lilongwe, Malawi, he observes, "see their stay in town through the prism of their rural aspirations", with nearly $90 \%$ intending to return home at some point. He further suggests that migrants are spiritually connected to their home villages and use Malawian traditions of witchcraft to establish and explain happenings in urban and rural areas, so that urban and rural spaces intersect in the migrant's lives. In this way, "the domain of the rural, both as the object of the moral imagination and as a geographical site, is constantly remade in relation to what migrants achieve and fail to achieve during their stay in town" [35]. Similarly, Michael Wood draws on Skaptadottir and Vojtaynska's concept of "the dichotomized lives" of Polish migrants "who work in Iceland in order to create a better life back home" and therefore maintain a "bifocal" view, by laying claims to two homes: "here" and "there. Wood deploys the concept of "rural cosmopolitanism" to capture this stretching of community identities over space or what we will call as double belonging [16]. On their part, Velayutham and Wise, use the notion of "trans-local village" to describe "a particular form of moral community based around village-scale, place-oriented familial and neighbourly ties that have subsequently expanded across extended space." Tamil Indian villagers who migrate to urban Singapore, they concede, replicate village activities and their "trans-local village" encompasses both economic and moral ties to the home community by sending remittances, serving as a conduit and providing support to other community members to migrate, and ... through "the replication or mirroring of village activities in the place of settlement." The socio-political structure of the village is therefore replicated in the migrant population in Singapore, and events and rites of passage in the village are also commemorated in Singapore. In this light, "the social field of the trans-local village is reproduced as much through the trans-localizing of affective regimes emerging from the village, while (rituals, sentiments and affect are means of inscribing locality onto bodies, creating a sense of boundary across extended space" [36]. This dovetails with Wood's conceptualization of the 
rural as a multi-dimensional concept which shapes the social and economic structure of rural localities and the everyday lives of people, who live, work or play in rural areas [16].

\section{Urban-Rural Reconceptualization}

In the face of the contemporary world system of social science, which is faithfully captured by the concepts of multi-locale and trans-local ethnography, we find the urban-rural dichotomy quite problematic. It represents a troublesome delineation of cultural areas and the homogenization of cultural identities. But local/so-called rural peoples are hooked up to the outside world through the phenomenon of migration and the ideas and influences acquired transform both urban and rural spaces in migrant's lives [16, 35, 36]. Although people migrate, they remain carriers of their culture. They recreate the so-called rural culture in the urban landscape thereby transforming it in specific ways. They are at the same time influenced by their new environments in novel ways, which might lead them to question their own initial cultural assumptions. When they eventually return to their homes, they become agents of change to their own culture. Kirsten Hastrup concedes that even the advent of the so-called postcolonial era (if there is anything like that), has not meant the emergence of new bounded wholes independent of history and geography. The world has become interdependent and "globalized" [37]. The basic concept of an "urban" or "rural" culture should be seriously scrutinized and questioned because demographic criteria are culture-bound. In addition, a rural area in one country may well be an urban area in another. Much really depends on how the state plans and shares resources among various regions. State socialist planning seems to support this vision particularly as people were able thanks to available but cheap transport networks to live in the countryside and work in town on a daily basis.

The concept of "rural" further conjures the idea of a homogenous and bounded cultural entity. This is yet another fiction because even within a given cultural complex, there is no unanimity. Culture is contestation and there are as many opinions, voices and sub cultures as possible within every given culture. Simultaneously, the location of a social actor makes truth and knowledge to be situational since culture is what the dominant class does. Therefore, even a rural environment is heterogeneous in terms of opinions and viewpoints. This is exactly in line with what Kistern called the "exotic view of culture" which assumed "the boundedness of cultural units and the confinement of the varieties of human consciousness within these boundaries" [37]. Gupta and Ferguson have called on anthropology and by extension, the social sciences to embrace changing trends in contemporary world marked by "rapid shifts in people, objects and ideas." These shifts, they argue, have transformed the notion of the "field" as a fixed territorial space. This is quite evident when considering "new tribes" like refugees, migrants, displaced and nomadic communities. They note that culture is not bounded and therefore does not occupy designated spaces. They observe that conceptions of bounded cultures are false because they do not account for people inhabiting borderlands nor do they factor in cultural differences of people occupying the same geographical space. They further assert that post-colonialism and globalization have heralded the idea of hybrid cultures in which concepts like identity and solidarity are no longer based on proximity to marked spaces and contact zones and thus make the case for a re-think of anthropological models of analysis [5, 41]. Following Arjun Appadurai [38], it is worth noting that the contemporary world is re-structured by the overarching effects of globalization such that it has become quite "de-territorialized" in ways that have altered the conception of "locality and space" [39]. Similarly Richard Fox and Andre Gingrich, argue that "of late, the notion of whole cultures or integrated societies has been questioned in the advent of new ideas of globalization, cultural flows, fragmentation and fluid signs which have been touted as definitive blows to anthropology's traditional objects of study: local communities of some order" [40]. There is therefore a general drift in anthropological epistemology towards the use of a more fluid methodology, such as multiple case studies, now that the notion of bounded exotic cultures is fizzling out. The tendency is increasingly towards multi-locale ethnography through multi-site study.

\section{Conclusion}

The future of the social sciences $[41,42]$ as a concerned human discipline depends on our ability to discard the community-study genre, the rural-urban dichotomy, nations as analytical categories in favor of a regional focus which can encapsulate both rural and urban systems in a common framework, while at the same time retaining the insights that derive from intensive analysis of processes on a small-scale. In other words, we need to study phenomena ethnographically from grassroots as well as from top-down perspective. This is because people are both multiply located and places are interconnected-be they rural or urban areas as the recourse to traditional medicine, dualistic religious inclination and urban agriculture suggests. We should understand the world as an unequally structured space where it is necessary to see global connectivity and mobility linkages between the rural and the urban as highly stratified processes. There is a dramatic, yet, unexplored potential for social anthropology in particular and the social sciences in general to unravel and expose these worldwide processes 
ethnographically or to put it in Burawoyian words, to study people in their time and space and by doing so, to get an insight into the lived experience of globalization. An analysis of local historical processes within any given region will foreground local ethnography within the extra-local context of larger historical processes and multiple flows. This will lead us toward a "critical junctions" perspective-the connections in space (and in and out of a place/in and out of a group), the relations through time, the internal and external relations of power and dependency, and what Wolf has called "the interstitial relations" between apparently separate institutional domains" [3]. In line with this theoretical path, we constantly need to document the specific impact of local, national, regional and global forces and flows on people's lives because of multiple connections and not to freeze them in either rural or urban space, but rather to see them as "rural-urban" and "urbanrural" in terms of hybridity and hyphenated identities and the blurring of urban-rural problems. This concern has also been articulated by Paul Clocke and associates' view to build a more interdisciplinary critical rural social science and to link this directly to broader societal and restructuring trends [8]. In other words, they point to the need for a malleable and robust political economy of rural space. Moreover, to look beyond physical/socially constructed boundaries to capture intersections between social construction and rural practice [10].

\section{Competing Interests}

Authors have no conflicting interests.

\section{Authors' Contributions}

NVP designed the main study, pretested and refined the research questions with the collaboration of TOB. TOB did the literature review and analysis while NVP translated relevant French language sources. Both wrote different sections of the draft, harmonized it and revised the manuscript.

\section{References}

1. Van Binsbergen W, 1998. Globalization and virtuality: analytical problems posed by the contemporary transformation of African Societies. Development and Change, 29: 873-903.

2. Caglar AS, 1997. Hyphenated identities and the limits of culture. In: Tariq Modood and Pnina Werbner (eds.). The Politics of Multiculturalism in the New Europe: Racism, Identity and Community. London: Zed Books, 169-186. ISBN-13: 978-1856494229.

3. Kalb D, Tak H, 2005. Critical Junctions: Anthropology and History beyond the Cultural Turn. New York: Berghahn Books. ISBN-10: 1845450299.

4. Bhabha H, 1994. The Location of Culture. London and New York: Routledge. ISBN 0415016355.

5. Gupta A, Ferguson J, 1997. Discipline and practice: "The field" as site, method, and location in anthropology. In: Gupta and Ferguson (eds.). Anthropological Locations. Berkeley, University of California Press, 1-45. ISBN-10: 0520206800.

6. Hoggart K, 1990. Let's do away with rural. Journal of Rural Studies, 6(3): 245-257.

7. Halfacree $\mathrm{KH}, 1993$. Locality and social representation: Space, discourse, and alternative definitions of the rural. Journal of Rural Studies. 9(1): 23-37.

8. Clocke P, Marsden T, Mooney PH, 2006. Hand Book of Rural Studies. London: Sage Publications Ltd. ISBN-13: 978-0761973324.

9. Mormont $\mathrm{M}, 1990$. Who is rural? Or how to be rural: Towards a sociology of the rural. In: Marsden $P$, Lowe $P$, Whatmore S (eds.). Rural Restructuring, Global Processes and their Responses. London: David Fulton, 2143. ISBN-10: 1853461113.

10. Clocke P, 2006. Conceptualizing rurality. In: Clocke P, Marsden T, Mooney P (eds.). Handbook of Rural Studies. London: SAGE Publications, 18-28. ISBN-10: 076197332X. 
11. Dyson T, 2003. HIV and urbanization. Population and Development Review, 29(3): 427-442.

12. Anarfi JK, 1993. Sexuality, migration and AIDS in Ghana: A socio-behavioral study. Health Transition Review, 7(3): 1-22.

13. Coffee M, Garnett G, Mlilo M, et al., 2005. Patterns of movement and risk of HIV infection in rural Zimbabwe. Journal of Infectious Diseases, 191(1): S159-167.

14. Coast E, 2006. Local understandings of, and responses to, HIV: Rural-urban migrants in Tanzania. Social Science and Medicine, 63: 1000-1010.

15. Anglewicz P, 2006. HIV infection, marital dissolution, and migration in Malawi. [http://paa2008.princeton.edu/download.aspx?submissionld=80483]

16. Woods M, 2011. Rural. Routledge. ISBN-10: 0415442400.

17. Inkeles A, Smith DH, 1974. Becoming Modern: Individual Change in Six Developing Countries. Harvard: Harvard University Press. ISBN-13: 978067406374063761.

18. Connor L, Samuel G, 2001. Healing Powers and Modernity. Traditional Medicine, Shamanism, and Science in Asian Societies. Westpont: Bergin and Garvey. ISBN-10: 0897897153.

19. Nyamnjoh F, Konings P, 1999. The Anglophone problem in Cameroon. Journal of Modern African Studies, 53(2): 207-229.

20. Neba AS, 1987. Modern Geography of the Republic of Cameroon. Philadelphia: Temple University.

21. Portes A, 1973. Modernity and development: a critique. Studies in Contemporary International Development, 83(Fall): 247-279.

22. Gusfield JR, 1967. Tradition and modernity: misplaced polarities in the study of social change. American Journal of Sociology, 72: 351-362.

23. Durkheim E, 1950. The Rules of the Sociological Method (Catlin GE, Trans. and ed.). Glencoe: Free Press. ISBN-10: 0029079403.

24. Spencer H, 1903. Social Statics. New York: Appleton. ISBN-10: 0911312331.

25. Titi P, 1996. Paganisme: Le Visage Actuel du paganisme. Reflextion d'un Anthropologue Camerounais sur la Religion Traditionnelle et les Survivances. In: Societes Africaines et diaspora, No. 2, Paris: L"Harmattan, 1938.

26. Little K, 1966. West African Urbanisation: A Study of Voluntary Associations in Social Change. Cambridge: Cambridge University Press. ISBN: 0521055652.

27. Foster GM, Anderson BG, 1978. Medical Anthropology. New York: John Wiley \& Sons.

28. Parrinder G, 1976. Africa's Three Religions. London: Clarendon Press. ISBN-10: 0859690962.

29. Mawoneke TS, King B, 1998. Impact of Urban Agriculture Research in Zimbabwe. [www.idrc.ca/eva.php]

30. Lomo Myazhiom AC, 1992. Religions, rivalites religieuses, autorites politiques et marriages au Cameroun sous mandate et tutelle entre 1914 et 1958. Societes, pouvoirs et religions en Afrique colonisee, XIXe-Xxe siecles. Villeneuve D’Ascq: Presses Universitaires du Septentrion, 100-123.

31. Ela JM, 1982. L'Afrique des Villages. Paris Karthala. ISBN: 2865370526. 
32. De Rosny E, 1974. Ndimsi-Ceux qui soignent dans la nuit. Etudes et Documents Africains. Yaounde: CLE. ISBN: R040184292.

33. Pigg SL, 1992. Inventing social categories through place: Social representation and development in Nepal. Comparative Studies in Society and History, 34(3): 492-513.

34. Geschiere P, 1995. Sorcellerie et politique en Afrique. La viande de autres. Paris Karthala. ISBN-10: 2865375218.

35. Englund $\mathrm{H}, 2002$. The village in the city, the city in the village: Migrants in lilongwe. Journal of Southern African Studies, 28(1): 137-154.

36. Velayuthan S, Wise A, 2005. Moral economies of a translocal village: obligation and shame among South Indian transnational migrants. Global Networks, 5(1): 27-47.

37. Hastrup K, 1993. The native voice and the anthropological vision. Social Anthropology, 1(2): 173-186.

38. Appadurai A, 1988. Putting hierarchy in its place. Cultural Anthropology, 3: 37-50.

39. Appadurai A, 1991. Global ethnoscapes: Notes and queries for a transnational anthropology. In: Fox RG (ed.). Recapturing Anthropology: Working in the Present. Santa Fe, NM, School of American Research Press. 191-210. ISBN-10: 0933452780.

41. Fox R, Andre G, 2002. Introduction. In: Anthropology, by Comparison. Andre G, Fox R (eds.). London and New York: Routledge, 1-24. ISBN-10: 0415260531.

42. Sorbo GN, 1988. Anthropology at home and abroad: A discussion of epistemological and ethical issues. In: Fahim H (ed.). Indigenous Anthropologists in Non-Western Countries. Carolina Academic Press, 153-163. ISBN-10: 0890891982. 